Portland State University

PDXScholar

Spring 6-19-2017

\title{
The Efficacy of Virtual Protest: Linking Digital Tactics to Outcomes in Activist Campaigns
}

Rina Lynne James

Portland State University

Follow this and additional works at: https://pdxscholar.library.pdx.edu/open_access_etds

Part of the Sociology Commons

Let us know how access to this document benefits you.

\section{Recommended Citation}

James, Rina Lynne, "The Efficacy of Virtual Protest: Linking Digital Tactics to Outcomes in Activist Campaigns" (2017). Dissertations and Theses. Paper 4008.

https://doi.org/10.15760/etd.5892

This Thesis is brought to you for free and open access. It has been accepted for inclusion in Dissertations and Theses by an authorized administrator of PDXScholar. Please contact us if we can make this document more accessible: pdxscholar@pdx.edu. 
The Efficacy of Virtual Protest:

Linking Digital Tactics to Outcomes in Activist Campaigns

by

Rina Lynne James

A thesis submitted in partial fulfillment of the requirements of the degree of

Master of Science

in Sociology

Thesis Committee:

Ginny Garcia-Alexander, Chair

Amy Lubitow

Robert Liebman

Portland State University

2017 


\begin{abstract}
Activists are increasingly relying on online tactics and digital tools to address social issues. This shift towards reliance on the Internet has been shown to have salient implications for social movement formation processes; however, the effectiveness of such actions for achieving specific goals remains largely unaddressed. This study explores how the types of Internet activism and digital tools used by activism campaigns relate to success in meeting stated goals. To address these questions, the study builds on an existing framework that distinguishes between four distinct types of Internet activism: brochure-ware, which is oriented towards information distribution; e-mobilizations, which treats digital media merely as a tool for mobilizing individuals offline; online participation, which is characterized by wholly online actions such as e-petitions or virtual protests; and online organizing, where organization of a movement takes place exclusively via the internet with no face-to-face coordination by organizers.

Ordinal regression models were conducted utilizing cross-sectional data from the Global Digital Activism Data Set (GDADS), a compilation of information on 426 activism campaigns from around the world that began between 2010 and 2012; additional data regarding the types of Internet activism used was also appended to the GDADS using source materials provided within the data set. The findings suggest that use of the Internet for mobilizing offline actions is negatively associated with campaign success, but that this does not hold true for protest actions organized without use of digital tools. Epetition use was also found to be negatively related to achievement of campaign goals.
\end{abstract}




\section{Table of Contents}

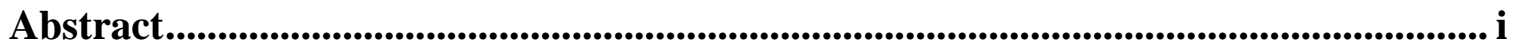

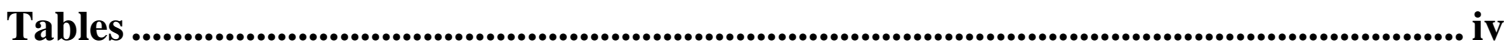

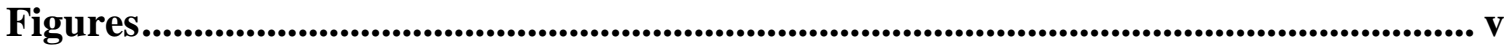

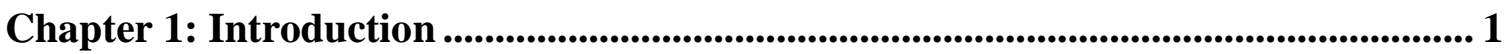



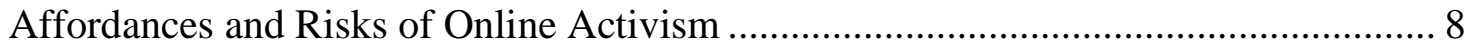

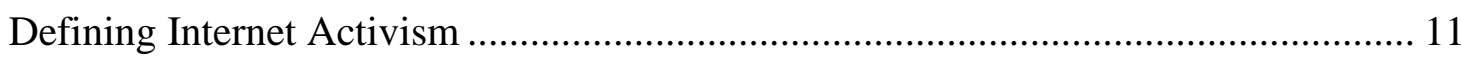

Theoretical Implications: Revising Theory and Updating Definitions ....................... 17

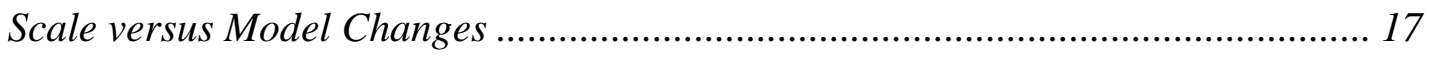

Shifts in Organizational Forms.................................................................... 20

Studying the Effectiveness of Internet Activism .............................................. 25

What Predicts Success? .................................................................................... 25

Measuring the Effectiveness of Internet Activism ................................................. 27



Chapter 3: Methodology................................................................................................................... 32

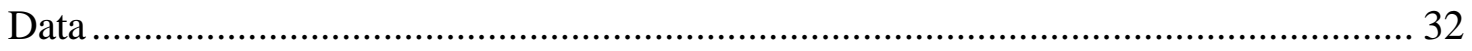

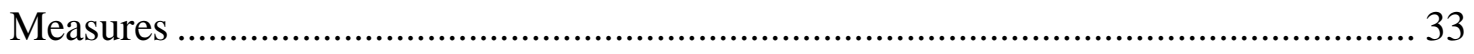

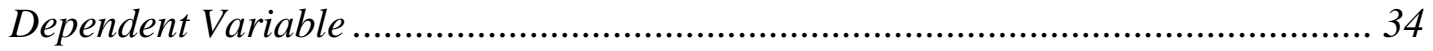

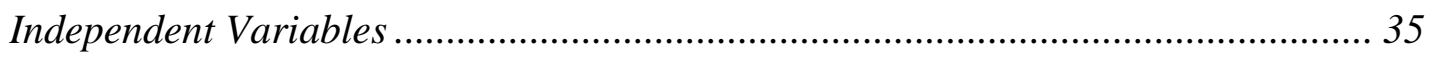

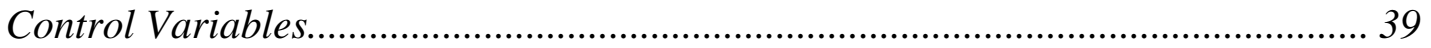


Analytic Plan

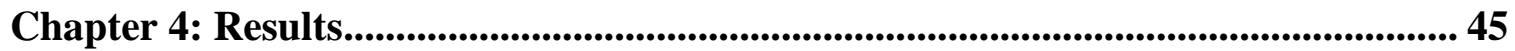



Ordinal Logistic Regression Results Predicting Campaign Outcome ........................ 48



Effectiveness of Types of Internet Activism ................................................... 51

E-petition Use and Implications for Efficacy ....................................................... 55

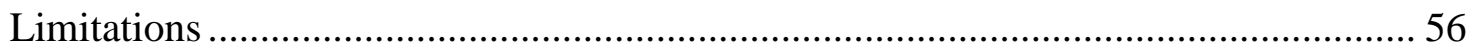

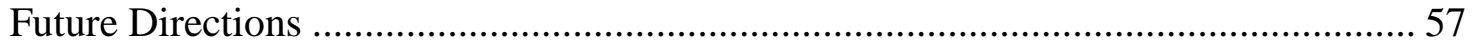

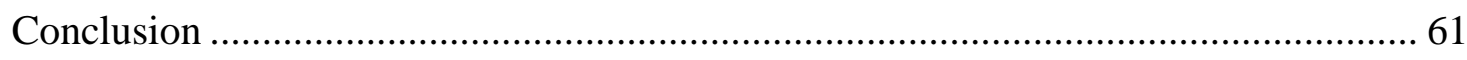






\section{Tables}

Table 1: Indicators for Categories of Internet Activism ........................................... 36



Table 3: Distribution of Outcome Across Predictors.................................................. 47

Table 4: Proportional Odds Ratios from Ordinal Logistic Regression Predicting Success 


\section{Figures}

Figure 1: Theoretical Implications of the Four Categories of Internet Activism ............. 19 


\section{Chapter 1: Introduction}

As the Internet continues to grow increasingly accessible across populations and geographic borders, its use has garnered a great deal of attention from those interested in exploring how digital technologies are shaping the social landscape and altering the ways that individuals communicate and form networks. Of particular interest is the question of whether online engagement plays a useful role in motivating or facilitating civic participation or, more broadly, social change. Activists worldwide are more frequently relying on information and communication technologies and digital media - that is, online participatory media such as websites, blogs, or social networking sites - to inform and connect individuals, creating interest in determining digital media's effectiveness as a means of disseminating information, mobilizing individuals for online and offline actions, and exerting influence on specific targets. Despite the existence of numerous studies examining the impact of Internet use for activism, previous research is somewhat unclear on how digital media is altering the activist landscape, with investigations into the implications of Internet activism offering disparate results in a number of areas.

Previous studies exploring the theoretical implications of Internet activism are in disagreement regarding whether digital media is altering the underlying logic behind social movement formation processes. Some work suggests that theoretical models such as the resource mobilization and political processes models must be revised or replaced in order for these frameworks to reflect how the Internet is altering the way that individuals are mobilized (Anduiza, Cristancho, and Sabucedo 2014; Bennett and Segerberg 2012; Earl et al. 2010). Other scholars argue that the Internet changes very little about the way 
that social movements form. Still others claim that the Internet is not only not changing the way that individuals mobilize, but that it is actually discouraging them from doing so all together (Couldry 2015; Kristofferson, White, and Peloza 2014; Schumann and Klein 2015).

In the case of studies identifying need for new theoretical models, the use of digital media as a mobilizing agent has been linked to profound differences in mobilization processes when compared to mobilizations not utilizing digital technologies; in particular, formal organizations are implicated as being less important to social movement processes than they were previously (Bennett and Segerberg 2012; Earl 2015). Scholarship suggests that activist mobilizations facilitated through the Internet rely less frequently on traditional, organizationally-brokered collective action, and more on a selfmobilized 'connective action' made possible through the use of communication technologies (Anduiza et al. 2014; Bennett and Segerberg 2012). Much previous theorizing on social movement formation and maintenance has emphasized formal organizations as necessary to mobilize individuals and provide resources for movements (Gamson 1975; McAdam 1982), and even scholars more critical of relying primarily on bureaucratic organizations have acknowledged the necessity of loose organizational coalitions (cadre organizations) for linking activists and building a broader movement (Piven and Cloward 1977). This suggests that if these organizations are truly being replaced or supplemented with digital technologies, standard theories are called into question and require theoretical revisions. 
Other scholarship indicates less revolutionary, but still salient, changes to social movement processes due to the increasing use of the Internet to facilitate protest actions. Even when not requiring complete replacement, resource mobilization theories still require significant adjustments to account for digital media's ability to potentially lower the costs of social movement participation and thus reduce reliance on resources (Earl 2010). Similarly, increased contact between organizations may not change the way that movements form, but may increase inter-organizational contact and communication, increasing the scale of social movement processes (Earl et al. 2010).

Earl et al. (2010) provide a potential explanation for variation in the findings regarding digital media's impact on movement formation processes by introducing a typological framework for examining Internet activism. They suggest that the findings of previous studies are so varied because they treat digital activism as a homogenous phenomenon with uniform impact, when in reality that are four distinct modes of Internet activism: (1) brochure-ware, which is oriented towards information distribution; (2) emobilizations, which treats digital media merely as a tool for mobilizing individuals offline; (3) online participation, which is characterized by wholly online actions such as e-petitions or virtual protests; and (4) online organizing, where organization of a movement takes place exclusively via the internet with no face-to-face coordination by organizers Through an analysis of previous studies, Earl et al. find that brochureware and e-mobilizations were frequently linked to scale-related changes in movement formation processes. In contrast, online participation and online organizing - found to be underrepresented in the literature compared to their rate of use by movements - were 
found to more frequently yield results suggesting changes to models of social movement formation were necessary.

Earl et al. (2010) suggest that future research not only take a more nuanced approach to investigating Internet activism, but that there is also need for exploration regarding how these forms of activism may relate to social movement efficacy. Contemporarily, the question of efficacy is relatively under-addressed in the literature, with previous work typically focusing on the effectiveness of Internet activism as it relates to mobilizing constituents for offline protest actions and largely ignoring the question of whether Internet activism is effective in exerting influence on specific targets regardless of the forms of participation involved (Anduiza et al. 2014; Boulianne 2015; Couldry 2015; Kristofferson et al. 2014; Robles, De Marco, and Antino 2013; Schumann and Klein 2015; Valenzuela 2013). In work that does exist exploring efficacy for achieving goals, individual forms of online participation are addressed without account for whether they were utilized in the context of a broader movement as only one tactic among a more varied repertoire of contention (Shulman 2009; Wright 2016). Similarly, the effectiveness of the specific digital media that are used to engage in such actions has only been examined without regard for the specific ways that activists used these tools, and the specific aims they hoped to achieve (Joyce, Rosas, and Howard 2013).

Given the dispute in findings for most other aspects of the literature relating to online activism, examinations of the efficacy of different types of activism and different digital tools are important because the varied results of previous research give cause to believe there may be differences in efficacy as well. Additionally, the previous work 
suggesting changes to movement formation processes does not address whether these changes are to the benefit or detriment of movements. Internet activism has been shown to frequently rely on 'weak-tie' networks of loosely-connected individuals instead of stronger ties typically built through formal organizations (González-Bailón et al. 2011; González-Bailón, Borge-Holthoefer, and Moreno 2013), which may result in more ephemeral movements instead of enduring ones (Earl 2010, 2015). While previous analysis suggests that these more transitory movements are not necessarily predestined to fail in achieving their goals, discussion on their implications for efficacy rely largely on speculation. The purpose of this study is to address these gaps and provide a more empirical and nuanced exploration of digital activism's effectiveness. Specifically, this work seeks to answer the research question: Are certain modes of Internet activism more likely to be effective for achieving stated goals? A second research question asks: Are certain types of digital media more likely to be effective for achieving stated goals?

To address this question, quantitative analysis of cross-sectional data is used to explore differences in the effectiveness of different modes of Internet activism. Data for the study comes from Global Digital Activism Data Set 2.0 (GDADS2), which consists of detailed information on more than four-hundred activism campaigns utilizing digital tactics. A unique feature of the GDADS2 is that it includes primarily textual information, providing links to campaign's digital media pages and to websites reporting on campaign activities; these source materials were utilized to append the data through a quantitative content analysis during which additional variables not initially included in the data were constructed. Of particular relevance is the construction of variables identifying which of 
the four categories of Internet activism outlined by Earl et al. (2010) were engaged in during the course of the campaign. As such, this study not only contributes to the literature by identifying more nuanced directions for future research, but also provides a very tangible contribution to the existing data and serves to inform future work by identifying factors that should be included in subsequent data collection efforts regarding online activism. In doing so, this study will help to develop a more detailed understanding regarding how activists' uses of the Internet relates to their ability to affect social change. 


\section{Chapter 2: Literature Review}

The Internet emerged as a tool for collective action almost as soon as it entered the homes of the general public. While initial Internet adoptions rates were relatively low, instances of early online communities using the Internet as a tool for engaging in protest actions or organizing mobilizations are plentiful as early as the 1990s. Initial examples of such cases include an online campaign focused on halting an IBM initiative to compile and sell directories of consumer data on CD-ROM, and Internet protests against changes in the terms and conditions of the then-popular website Geocities (Gurak 2014). Internet communication has also been identified as an important tool in the organizing of the 1999 protests of the WTO in Seattle (Smith 2001) and in the 2004 strategic voting movement, where liberal voters in swing states mitigated the risk of voting third-party (and potentially increasing the chances of a Bush victory) by 'trading' votes with residents of states where one mainstream candidate was expected to win by a large majority (Earl and Kimport 2011).

While the online environment has grown increasingly complex and the ways that individuals connect via the Internet has changed substantially, the many tangible benefits of Internet-based communication ensured that the web has continued to serve as both a tool for protest and a space for connecting and organizing activists. Research on online civic engagement in the United States and Europe indicates that $44 \%$ of individuals have signed an online petition, $11 \%$ have used social media to join an activism campaign, and

4\% have used the Internet to organize an action or coordinate a meeting (Newman 2012). Accompanying this increasing reliance on the Internet has been a shift away from 
reliance on formal social movement organizations (SMOs) and non-governmental organizations (NGOs) - a trend which has salient implications for both theoretical models of social movement formation and, potentially, the effectiveness of their efforts.

\section{Affordances and Risks of Online Activism}

Internet-based communication offers numerous benefits that explain its popularity as a tool for activism, including increased communication speed and reduced communication costs. Not only do these features facilitate increased citizen-to-citizen communication, but they also allow the Internet to serve as both a means of communication and a broadcast medium which offers instantaneous access to the most up-to-date information, providing a substantial advantage over other forms of communication and more traditional broadcast channels (Garrett 2006). Online communication also "allow the messages tied to these movements to have a broader reach... and a higher degree of interactivity" (James 2014:17). These advantages are especially helpful in organizing offline mobilizations, where mobile communication technologies can help reduce the information asymmetries that traditionally emerge between activists and authorities during protests. While once police had an advantage in being able to surveil and share information amongst themselves, citizens can now observe and report on police actions to keep all members of a protest informed (Earl et al. 2013).

In considering these affordances of digital communication, some scholarship argues for differentiating between the Internet as a tool for communication and the Internet as a space for communication (Aouragh and Alexander 2011; Castells 1999, 
2012). In the case of the former, web-based communication such as that occurring over social media is primarily instrumental - the Internet as a medium is the most effective means of information dissemination and engaging in one-to-one or one-to-many communications, and is not substantially different from more traditional communications forms such as the telephone or broadcast television. In the case of the latter, however, "space refers to offering a dynamic ability to shape opinion and contribute to the "tipping point"” (Aouragh and Alexander 2011:1348). As a space, the Internet creates both 'spheres of dissidence' (Aouragh and Alexander 2011) or 'spaces of autonomy' (Castells 2012) where dominant ideologies and authorities may be challenged and public opinions may be shaped, and a 'space of flows' which

means that the material arrangements allow for simultaneity of social practices without territorial contiguity. It is not purely electronic space nor...a "cyberspace," although cyberspace is a component of the space of flows. First, it is made up of a technological infrastructure of information systems, telecommunications, and transportation lines. The capacity and characteristics of this infrastructure and the location of its elements determine the functions of the space of flows, and its relationship to other spatial forms and processes. The space of flows is also made of networks of interaction, and the goals and task of each network configurate a different space of flows (Castells 1999:295).

The Internet is both a tool offering simple communication and a space in which connection, collaboration, and interaction occur. The concept of a space of flows emphasizes how the networks enabled by the Internet reduce the need for 'territorial contiguity' - or what has been termed 'copresence' in other literature (Earl and Kimport 2011) - to engage in unified actions. It is not only the need for copresence that has been reduced, but also the need to engage in synchronous actions; while activists once needed 
to be in the same place at the same time, online communication has enabled multiple forms of action that may be completed asynchronously from any number of locations.

In discussing these affordances, it is also important to note that 'the Internet' is not one monolithic tool or space, but is comprised of numerous websites and media platforms which may vary in the specific affordances they offer (Earl et al. 2013; Fenton 2011; Milan 2015). Platforms such as Twitter are ideal for broadcasting small amounts of information to large numbers of people in real time (Earl et al. 2013), but its design is less suited to more detailed, behind-the scenes organizing. Similarly, some platforms provide more means of directly addressing targets while others offer more anonymity this is partly a consequence of design and partly a consequence of the perceived possibilities that inform activists' use of these technologies. The variation in affordances across social media have made it so that "social media are actors in their own right, intervening in the meaning-making process of social actors by means of their algorithmic power" (Milan 2015:888). All online platforms may have unique features and benefits, but they are not necessarily uniform. Similarly, some come with greater risk.

While information and communication technologies (ICTs) offer numerous benefits for engaging in activism, there are also a number of potential constraints that may arise when activists rely on these tools. These tools may be used to create 'spheres of dissidence' or 'spaces of autonomy' that allow activists to challenge dominant structures and ideologies, but they may also increase the risk of activist repression (Salter 2014; Shirky 2011). There is a certain degree of publicity that accompanies the dissemination of information online, which may increase the visibility of individuals 
activists and put them at risk of intense retaliation (Salter 2014). While some online platforms allow for anonymity, these also frequently offer fewer affordances for organizing. Additionally, the Internet as a whole is not without risk of censorship that may undermine activists efforts; digital tools may become functionally useless when flows of information become limited or entirely repressed (Shirky 2011).

Less insidious but still detrimental is the possibility that the many voices that emerge on digital platforms may make it difficult for movements to produce a cohesive message. Some research suggests that movement organizers may try to frame an issue in a particular way, but that "often individual messages would constitute a challenge to the organization but the lack of time and resources prevented organizers from engaging with such discussion" (Fenton 2011:187). In these cases, organizers lose a certain degree of control that can prove challenging and potentially undermine the movement's message.

\section{Defining Internet Activism}

Despite potential risks, the affordances outlined above not only make the Internet a convenient activist tool, but have also led to the emergence of a number of digital tactics. Together, these actions create 'digital repertoires of contention' that activists may draw from over the course of a movement. The repertoire of contention may be viewed as "the whole set of means that a group has for making claims of different kinds on different individuals or groups" (Tarrow 1997:328); these means of making claims may be culturally constrained by what is considered to be appropriate while also being limited to what tactics are realistically possible (Tilly 1978). A digital repertoire of contention, then, may be thought of as the means of claim-making that are available to activists in the 
online environment. The intense variation in actions that arises from the numerous options afforded by these digital repertoires of contention makes it important to understand what, specifically, constitutes 'Internet activism' and how the different tactics in these digital repertoires of contention may be influencing social movements.

Several attempts have been made to define and conceptualize Internet activism in its varying forms. There are a number of innovations found in digital repertoires of contention, some of which mimic actions that have historically been included in movements' repertoires of contention and others which depart from these previous tactics (Garrett 2006). Mobilization for traditional protests may be organized by the Internet with the only salient difference being that the individuals in attendance are more loosely affiliated than in the protest events of the past. Conversely, actions that once took place in the physical world are now being reproduced online - letter-writing campaigns and petitions, for example, now frequently take place wholly on the Internet (Earl and Kimport 2011; Garrett 2006). Similarly, acts of protest may now take place on the Internet, with activists engaging in "'Electronic Civil Disobedience' and 'hacktivism'...efforts to conduct actions in an ICT-mediated space consistent with the philosophy of civil disobedience" (Garrett 2006:12).

Other scholarship has worked to define and conceptualize Internet activism more explicitly, developing categorizations of different forms of Internet activism meant to lend a greater degree of specificity to discourse and empirical investigations on the subject (Earl et al. 2010; Van Laer and Aelst 2010; Postmes and Brunsting 2002). Van Laer and Aelst (2010) situate digital tactics along two axes, defining them as either high- 
or low-threshold (with the threshold being defined by the amount of risk and commitment a certain action entails) and either Internet-supported or Internet-based, with the former being more traditional tools that are simply "easier to organize and coordinate thanks to the Internet" (Van Laer and Aelst 2010:1148) and the latter being actions that actually occur wholly online. Examples of low-threshold actions include legal demonstrations, monetary donations, or consumer behavior in the Internet-supported category, and online petitions or email-writing campaigns in the Internet-based category. In contrast, highthreshold actions might include violent actions, destruction of property, sit-ins, or protests on the Internet-supported side, and 'hacktivism,' culture jamming, or protest websites on the Internet-based side.

Postmes and Brunsting (2002) provide a similarly structured typology with two different axes, defining actions as either persuasive or confrontational, and collective or individualistic and holding that these same orientations are reflected in both digital tactics and offline tactics. The collective/individualistic descriptor distinguishes between actions that can be engaged in individually (such as letter writing) and actions that require the participation of many members in a group (such as petitions). Similarly, the persuasive/confrontational axis distinguishes between actions aimed at persuading a target (such as petitions, lobbying, or letter-writing) and actions aimed at confronting a target (such as civil disobedience, striking, or hacktivism).

These two typologies have similar structures but different ways of conceptualizing activism that originates or occurs online. However, both fail to fully account for the range of actions that may be carried out using the Internet. In both cases, 
Internet activism is implicitly defined as the use of the Internet for protest; however, investigations into Internet activism suggest that activists engage in a number of activist behaviors online, not all of which are directly related to protest.

In examining activists' digital participation, Earl et al. (2010) suggests a third way of categorizing their online tactics. Instead of positioning actions along intersecting axes related specifically to protest, Earl et al. present a typology of four distinct modes of Internet activism: (1) brochureware, which is activist-created content oriented towards information distribution; (2) e-mobilizations, which use the Internet as a tool for mobilizing individuals offline; (3) online participation, which is characterized by wholly online actions such as e-petitions or virtual protests; and (4) online organizing, where organization of a movement takes place exclusively via the Internet without face-to-face coordination by organizers.

While all three typologies of Internet activism offer useful ways of thinking about Internet activism, they have limitations. In particular, Postmes and Brunsting (2002) and Van Laer and Aelst (2010) fail to account for the variety of ways that activists may use the Internet; they identify a useful way of conceptualizing use of the Internet for protest actions, but ignore the implications for information dissemination or organizing. Earl et al. (2010) address this omission with their own framework, which is more comprehensive but fails to fully delineate between online participation and brochureware, and what actions fall outside the scope of the typology entirely. This is partially a consequence of how Internet-based communications have evolved over the past two decades - at the time of Postmes and Brunsting's writing, social media was nowhere near as culturally 
ubiquitous as it would grow to become, and even at the time of Earl et al. and Van Laer and Aelst's publications, sites such as Facebook and Twitter were only beginning to embed themselves into activists' digital repertoires of contention. As such, these studies account only for the actions that were popular on traditional activist websites and, individually, are less useful in defining the boundaries of participation that become blurred when the affordances of social media are considered.

While some actions, such as 'liking' a Facebook page, are often criticized for not counting as 'real activism,' the typology provided by Van Laer and Aelst (2010) is one that would tolerate including such a behavior as a low-threshold action; it could simply be argued that social media affords even lower-threshold actions than were previously available. In other cases, however, where an action should be situated is not so clear. Distinguishing between brochureware and online participation becomes problematic as the line between information distribution and online protest becomes more difficult to define. Is an isolated tweet related to an issue an act of protest, or is it merely information distribution? Does uploading a video from a protest to YouTube count as dissent, or is it only disseminating knowledge? Earl et al. (2010) define online actions as occurring when "websites allow visitors to actually participate in an action while online (432) and brochureware as occurring when an act is meant "only to provide information to visitors without facilitating online interaction (often with the notable exception of facilitating donations)" (430). This definition excludes information broadcasting aimed at organizing individuals offline, which is relegated to its own separate category as e-mobilization. While sufficient when the discussion is limited to the traditional websites Earl et al. are 
analyzing, in the case of social media these definitions become insufficient. Social media platforms are not designed by the activists posting content, but by the platform developers. As such, it is important to distinguish between opportunities for participation provided by the broader movement or campaign, such as when a campaign organizer creates a page that can be 'liked,' and opportunities for participation afforded by the social media platform itself, such as when an individual champions a cause on Twitter or uploads a video that can be 'liked' or shared.

In considering what counts as online participation, the answer to these uncertainties may be addressed in part by considering the motivations for an action as well as its consequences. In the majority of cases, the goal of uploading video footage or speaking out on an issue is largely to raise awareness and spread information, relegating it squarely into the category of brochureware. In contrast, 'liking' a Facebook page is wholly oriented towards engagement with content. In the case of the latter, while the platforms on which these actions are undertaken may provide, as part of their features, minimal avenues for interaction, that is not their larger purpose. More importantly, actions such as isolated tweeting or posting YouTube videos provide no meaningful link to a larger movement via these online platforms; when encountered, another individual may be able to interact with such content, but they are not engaging with the broader movement because there is no connection, suggesting it is not true participation. This linkage to a broader whole should be considered an important defining feature of online participation. 
In some cases, this may require making distinctions between online participation and other forms of online activism based on small details. For example, content on Twitter has the potential to be isolated or part of a broader movement, depending on which affordances are utilized. Movement- or campaign-specific hashtags provide a way of connecting isolated content to a larger whole, crossing the boundary from brochureware to online participation. This is because hashtags are both a functional and symbolic inclusion that literally organize small amounts of content into a more meaningful aggregate while also "having the interdiscursive capacity to lasso accompanying texts and their indexical meanings as part of a frame. Linkages across hashtags and their accompanying texts...frame [hashtags] as a kind of mediatized place" (Bonilla and Rosa 2015:6).

\section{Theoretical Implications: Revising Theory and Updating Definitions}

Conceptualizing and classifying all types of Internet activism, not simply protest actions, is an important step in exploring how the increasing use of ICTs by activists is impacting social movements. Empirical work suggests a number of implications, including the need for adjustments to models of social movement formation, revisions to dominant theories, and the updating of definitions for key concepts such as collective action and collective identity (Bimber, Flanagin, and Stohl 2005; Earl 2015; Earl et al. 2010; Milan and Hintz 2013).

\section{Scale versus Model Changes}

There is a great deal of contention in the literature regarding Internet activism's implications for social movement theory. Some work suggests that minimal revisions to 
theory are necessary, while other investigations identify extensive changes in the underlying processes behind social movement formation (Anduiza et al. 2014; Bennett and Segerberg 2012; Bennett, Segerberg, and Walker 2014; Earl et al. 2010). One explanation for these disparate findings is the tendency for empirical work to treat Internet activism as a homogenous phenomenon with consistent implications (Earl et al. 2010). In failing to account for the variety of ways in which activists use digital tools, empirical studies into the consequences of these actions may fail to identify significant variation in the impacts of different types of online activism.

A review of previous research suggests that the four types of Internet activism identified previously - brochureware, e-mobilization, online participation, and online organizing - are linked to different theoretical implications (outlined in Figure 1) (Earl et al. 2010). Research examining brochureware and e-mobilization sometimes identified online activism as having no impact on theoretical models of social movement formation. For these studies "theoretical approaches can be applied unproblematically. This research prizes long-term bonds of trust and commitment built through face-to-face interactions between activists. Personal ties are thought to be critical to mobilization (Tarrow 1998; Rucht 2004), as are the social networks those relationships build and maintain" (Earl et al. 2010:426). More frequently, brochureware and e-mobilizations were also linked to 'scale' changes in theory. Scale changes suggest some differences between movements that use the Internet and movements that do not, but also hold that

Although the Internet may let groups disseminate information quickly (Myers 1994; Ayres 1999), reduce the cost of online communication (Peckham 1998; Fisher 1998), and/or enhance the ability of groups to create and represent broad online coalitions through links to other websites (Garrido and Halavais 2003, it 
doesn't change who activists are, what activists do, or how they do it in some more fundamental way...the number of SMO and network connections has risen because of Internet usage, resulting in much larger, if ephemeral, mesomobilizations (the mobilization of groups) and coalitions. But the underlying dynamics driving these mesomobilizations are just accentuated versions of the dynamics that have long been thought to drive mesomobilization (Earl et al. 2010:428)

For findings in this area, ICT use has scaled up social movement mobilizations, but has not altered the underlying processes behind movement formation in any fundamental way.

Figure 1: Theoretical Implications of the Four Categories of Internet Activism



Online participation and online organizing were also sometimes linked to scale changes, but most commonly research investigating these particular forms of Internet activism linked these tactics to changes in models of social movement formation, suggesting a need to completely revise current theoretical explanations. Studies identifying model changes indicated that the use of ICTs had a major impact on the underlying processes of movement formation and that "basic theoretical assumptions 
and/or robust social movement explanations don't as readily explain the dynamics of some types of Internet activism" (Earl et al. 2010:426). For example, theories focusing on resource mobilization may no longer apply because "the lower cost of social action online has diminished the importance of resources in some social movement contexts" (Earl et al. 2010:426). It is important to note that online participation and online organizing were the only types of Internet activism that corresponded to model changes in this review.

\section{Shifts in Organizational Forms}

Research examining slightly more recent movements has suggested that online participation and online organizing are not the only types of Internet activism that require rethinking models of social movement formation. Work on movements such as Occupy Wall Street and the los indignados movement suggest that these movements engaged in e-mobilizations, but did so without relying heavily on the formal organizations and coalitions that are upheld as important in a great deal of prior theory, suggesting model changes may be necessary as the role of formal organizations is diminished. While such organizations once played an important role in organizing movements, their importance has been reduced as they are "eclipsed by networked organizational forms that [scholars] characterize as robust, adaptable, and high maneuverable in the face of conflict" (Garrett 2006:15). This suggests that increased ICT use is impacting models of formation so that underlying logic behind movements has shifted from organizationally-brokered collective action to what has been termed a logic of 'connective action' (Bennett and Segerberg 2012). The logic of connective action is characterized by the self-organization of 
networks and the absence of conspicuous organizational forms, which is accompanied by the increasing significance of personalized, individualized connections to movements. These personalized connections take the place of identification with organizational ideologies and, when formal organizations are present, they are frequently in the background - not the forefront - of movements.

This self-organization is a process with many parts. Potential participants must be recruited, and some sense of organization must emerge in order for online organizing to mobilize individuals to engage in connective action. For movements utilizing this new organizational logic, digital ICTs are the mechanism through which these processes occur; online platforms are used to recruit movement participants, instead of organizations playing a key role in disseminating information about a movement, influential online actors diffuse information to potential participants and expose a critical mass of individuals to the movement (González-Bailón, Borge- Holthoefer, and Moreno 2013). This process is enabled when, at the beginning of the recruitment process, random 'activation seeds' are planted on a number of digital platforms. These activations seeds are nodes of content diversely placed, which maximizes the possibility of recruitmentrelated content reaching the center of a large network and being exposed to high numbers of participants (González-Bailón et al. 2011). These pivotal actors share content and create 'information cascades' - critical masses of information that create broad exposure as they move through networks. Through this process, a small group of initial actors can capture the attention of an influential user and broadly diffuse information online, amplifying a message, increasing exposure, and recruiting participants. 
During this process of diffusion across social networks, digital platforms serve as 'technological stitching mechanism,' or the actual scaffolding which creates the infrastructure of a movement and connects loose networks of individuals (Bennett et al. 2014). The linkages between digital platforms create and reinforce linkages between networks of individuals and enable distribution and curation of movement content and its transmission and integration across the broader Internet. During this process, the many actors who engage with the movement on these platforms, first exposed by those central to their networks, come together so that "The many small and fitful contributions of the crowd, whether in production, curation, or dynamic integration, are all potentially important" (Bennett et al. 2014:250). These networks are primarily composed of individual actors, though formal organizations may not be entirely excluded; their role is, however, increasingly diminished compared to movements that emerged prior to the existence of online networks.

The increasing prevalence of this connective action has two significant consequences. The first is that the loosely-networked organizations that do form may be fundamentally different from those that emerge when formal organizations serve to broker connections within a movement. Movements utilizing this logic of connective action have been found to include participants that are socio-demographically distinct; in comparing participants in protests organized online to those in protests organized primarily by SMOs or NGOs, participants engaging in connective action were found to be younger, less likely to have a formalized group membership, more likely to be unemployed, and more educated (Anduiza et al. 2014). This suggests that those 
mobilized through connective action are not the same individuals who might be mobilized through more traditional collective action. Additionally, the networks mobilized through this logic are typically comprised of weak-tie networks with fewer strong connections between individuals (Walgrave et al. 2011).

The second consequence of this connective action is that, as mentioned previously in the discussion on model changes, the theoretical models of social movement formation processes require some serious revisions. Resource mobilization theory, for example, holds formal organizations as central for accumulating the necessary resources and connections to exert real political influence and suggests that without them "groups lack the organizational resources needed to generate and sustain social insurgency" and "are handicapped by their lack of such traditional political resources as votes, money for campaign contributions, etc." (McAdam 1982:29). The political process model similarly emphasizes the need for formal organizations to maintain connections between members, establish solidarity incentives, and provide leadership for a movement (McAdam 1982). However, modern ICTs make these features of SMOs less necessary because they undermine a key assumption of these theories: that organizing and mobilizing individuals is inherently costly.

Historically, this may have been true; prior to the Internet, mass communication was expensive, organizing protest actions required substantial investment, and selective incentives to persuade against free-riding were necessary and costly. For the resource mobilization and political process perspectives then, "Organizations were seen as a method of collecting and deploying resources, and as entities that could manage the 
provision of selective incentives to encourage participation" (Earl 2015:37). However, as movements increasingly began utilizing ICTs and increasing the variety of actions in their digital repertoires of contention, these costs were drastically reduced and alternative possibilities emerged. Costliness of organizing and the problems of encouraging participation that were once positioned as an inherent issue for social movements diminished, suggesting that "traditional collective action theory represents an important subset of a broader range of theoretical possibilities - a subset that applies under certain conditions that were ubiquitous historically but that are no longer universally present when collective action occurs" (Bimber et al. 2005:367). The need for formal organizations, then, is no longer obligatory for movements but may be a necessity only in certain circumstances.

Many of the functions once facilitated by SMOs, such as organizing protest events and increasing movement visibility, are easily shifted to online communications. However, there may still be many instances where these organizations are valuable to movements. Many mobilizations that occur via ICTs are ephemeral in nature, which may make organizations sometimes necessary because "A time-focused goal does not require an enduring movement, and thus returns to investments in creating SMOs might be minimal or negative. Time-focused goals also fit well with a flash activism model of power. But, if one requires long-term, persistent action to achieve a goal - a goal for which flash activism is unlikely to be successful - then SMOs provide a more durable infrastructure for the challenge" (Earl 2015:46). Similarly, some circumstances may require more stable networks, such as when the activism is especially high-risk or legally 
dubious; in these cases, the strong-ties afforded by SMOs and their accompanying networks may be beneficial (Earl 2015).

\section{Studying the Effectiveness of Internet Activism}

\section{What Predicts Success?}

Defining success for social movements is not a simple task. There are a number of possible movement outcomes with varying implications, including official recognition, policy changes, cultural changes, or changes to the social structure (Giugni 1998). As such, empirical work examining social movement outcomes defines success in varying ways, ranging from achieving stated goals to influencing broader culture.

Conceptualizing success as the achievement of specific goals has benefits and disadvantages; while it allows for more easily quantifying outcomes, it makes it difficult to examine the success of broader movements, instead frequently focusing on the success of specific organizations or campaigns (Gamson 1975; Giugni 1998; Joyce, Rosas, et al. 2013). Gamson explores outcomes at the organizational level, suggesting two measures of success - the procurement of new advantages and formal recognition by a target. Together, they allow for four possible outcomes: (1) full response, in which both new advantages and acceptance are obtained; (2) preemption, when new advantages are received but no official recognition or legitimacy is obtained; (3) co-optation, where acceptance is given but no tangible benefits follow; and (4) collapse, when an effort is entirely unsuccessful and eventually disbands. This typology is useful, but "it has also put some limits to research, for it brought the focus on the organizations instead of on the broader cycles of protest, which may include various movements whose combined effect 
might be more important than the impact on a single challenging group" (Giugni 1998:383).

This typology is also limited in that it accounts only for the purposeful impacts of movements based on the stated aims of challenging groups, while failing to account for potential gains in the collective good that are not linked to initial goals (Amenta and Young 1999). Additionally, these definitions are predisposed to recognizing only policy changes or institutional recognition as success, but are a poor measure of broader change identified in other studies on movement outcomes, such as biographical or life-course consequences (McAdam 1999).

Despite the varying measures of success, previous empirical work has identified several factors that contribute to success regardless of how it is measured. As discussed previously, formal organizations are frequently cited as important components of a successful movement (Gamson 1975; Giugni 1998). Even among work critical of placing too great an emphasis on hierarchical, bureaucratic organizations, the need for coalitions of organizations to bridge social networks and facilitate protest actions is recognized (Piven and Cloward 1977). The ability to create disruption has also been shown to be essential in achieving movement goals (Piven and Cloward 1977). In addition to a movement's organizational structure, external social factors are found to be important to movement success. Support from third parties and elites is upheld as necessary in empirical work supporting resource mobilization and political process theories (Gamson 1975; McAdam 1982). Similarly, the framing and narratives surrounding issues and their 
ability to effectively generate public support also emerges as a key factor in whether a movement succeeds or fails (Giugni 1998; Polletta 1998).

\section{Measuring the Effectiveness of Internet Activism}

Most commonly, work examining the effectiveness of Internet activism has discussed efficacy in terms of online efforts' ability to mobilize constituents for offline actions, largely ignoring the question of whether digital tactics are effective in exerting influence on specific targets and achieving meaningful change. Additionally, among these existent studies, the discourse surrounding Internet activism's usefulness for mobilization is somewhat contentious, with a number of empirical works indicating that digital tactics can be effective for mobilization (Anduiza et al. 2014; Bennett and Segerberg 2012; Boulianne 2015; Maireder and Schwartzenegger 2011; Mercea and Funk 2014; Robles et al. 2013; Segerberg and Bennett 2011; Valenzuela 2013; Vissers and Stolle 2014) and other research arguing that online tactics actually reduce individuals' likelihood to participate in offline actions (Kristofferson et al. 2014; Schumann and Klein 2015).

Implicit in these investigations is the assumption that offline mobilization is the only worthwhile goal of Internet activism, and that only through the facilitation of offline actions are digital tactics useful for effecting change. This emphasis on offline mobilization is perhaps unsurprising; previous scholarship on social movements focuses heavily on mobilization, with discussions on how to achieve success emphasizing the need for individuals to engage (or, in some cases, purposefully disengage) in orchestrated actions within physical spaces (Piven and Cloward 1977). Given the emphasis 
traditionally placed on mobilization, a focus on the use of the Internet for coordinating physical demonstrations or similar forms of protest is arguably a logical continuation of previous discussions. However, it is important to consider that these offline actions were, until the advent of digital media, largely the only possible forms of action. As such, it is limiting to discuss Internet activism's usefulness only in terms of how effectively it mobilizes individuals offline, and it is misguided to ignore the potential for Internet activism to effect change even when activists' online engagement is not solely or primarily aimed at offline mobilization.

The few discussions of efficacy outside the context of mobilization are also frequently limited and insufficient. Many focus only on activists' perceptions of their online participation (Brunsting and Postmes 2002; Postmes and Brunsting 2002), or entirely eschew empirical investigation in favor of making purely speculative predictions about the implications of digital tools for efficacy (Earl 2010; Earl et al. 2010; Garrett 2006). The small body of empirical work that does focus on efficacy focuses largely on success as goals met, and frequently only examines online participation in one or two types of low-threshold actions. E-mail writing campaigns have, for example, been found to be ineffective because large influxes of emails are frequently ignored by targets receiving them (Shulman 2009). Similarly, a study on e-petition use in Britain indicated that these efforts rarely lead to the policy changes they typically seek to achieve (although, individuals in the study also indicated they were not necessarily measuring the success of the petition by whether new advantages were obtained, and frequently cited increasing awareness or publicity as a success of these actions) (Wright 2016). 
These findings may be of interest to those concerned with the efficacy of such actions, but they also remove such tactics from the context of a larger movement, offering little useful information about the implications of such actions for an organization, campaign, or movement's overall effectiveness. They also draw conclusions about the efficacy of low-threshold actions, without acknowledging the potential variation that exists between the digital media and digital platforms used to execute such actions. As discussed previously, different digital platforms present different sets of affordances and constraints, suggesting that findings about a specific tool such as e-mail or e-petitions may not be generalizable to other forms of digital media or platforms.

Slightly different results emerge in research that does contextualize online actions within activism campaigns, finding that campaigns limiting their digital media use to only a small number platforms were more likely to achieve success (Joyce, Rosas, et al. 2013). However, these findings are also limited in that they account only for the specific platforms used by activists, while failing to account for the purpose underlying that use. Similar to other research on Internet activism, there is no attention given to the existence of multiples types of Internet activism, and no effort made to account for how, specifically, activists are using these tools.

\section{Hypotheses}

Overall, in the literature surrounding Internet activism there is a relative dearth of work examining the issue of efficacy, and what little research on efficacy exists fails to account for the enormous variations in activists' use of digital tools. The existent literature suggests that Internet activism is a varied, not homogenous phenomenon, and 
that the different types of actions that activists may engage in online have differing implications for social movement theory. Similarly, research on ICTs indicates that the digital platforms through which these actions take place are varied in the benefits and risks that they offer; as such, it is plausible that the types of digital media used by may also have implications for efficacy. Given these findings, I propose the following hypotheses in response to the research questions:

$H_{1}$ : Certain types of Internet activism will be more effective for meeting stated goals.

$\mathrm{H}_{2}$ : Certain digital platforms will be more effective for meeting stated goals. In accordance with the aforementioned literature, a three-level typology of success was adapted from Gamson's (1975) work; based on stated goals, outcomes are measured as achieving total success (all campaign goals achieved), partial success (cooptation or preemption, in Gamson's terms), or no success (collapse). Similarly, Earl et al.'s (2010) typology of Internet activism is used define the varying ways individuals use ICTs to engage in activism. It should be noted that these typologies are used to frame analyses at the campaign level, not the social movement level. While there are similarities, a campaign is generally considered to be only one part of a social movement, defined as "a sustained, organized public effort making collective claims on target authorities" (Tilly and Wood 2013:5). Full social movements, in comparison, also include a variety of forms of political action alongside "concerted public representations of WUNC: worthiness, unity, numbers, and commitment” (Tilly and Wood 2013:5). However, because campaigns are a subsidiary element of a social movement, their 
success is tied to social movement success. Additionally, campaigns are often briefer and have more concretely defined goals, making them an ideal unit of analysis for exploring the outcomes of digital activism.

By examining the outcomes of campaigns utilizing digital tactics and tools, the analysis will improve on previous studies that make broad generalizations about online activism without accounting for the nuanced ways that digital technologies may be used. As was previously addressed, not all ways of engaging in activism online are identical. Activists use ICTs for a number of different purposes - to disseminate information, to facilitate offline protest, to engage in protest, and to organize. Additionally, they engage in these actions across a diverse array of platforms, some of which may be better suited to certain tasks than others. By exploring how engagement in different types of Internet activism and with different types of digital tools relates to outcomes, the consequences of a trend towards increasing reliance on ICTs can be better understood, and future activist strategies may be better informed. 


\section{Chapter 3: Methodology}

Data

Data for the study originates from the Digital Activism Research Project at the University of Washington (Joyce, Howard, and Rosas 2013). Since its inception in 2012, the project has endeavored to collect comprehensive data on digital activism campaigns, which are defined as a campaign that was "an organized public effort, making collective claim(s) of target authority(s), in which civic initiators or supporters use digital media" (Joyce et al. 2013: 10). The effort culminated in the release of two data sets - the Global Digital Activism Data Sets (GDADS 1.0 and 2.0) - providing detailed information about digital activism campaigns occurring over the past two decades. The first set released, the GDADS 1.0, includes information on more than 1,000 cases of Internet activism dating as far back as 1982, while the second version of the data set, the GDADS 2.0, includes a smaller number of cases, but offers higher quality information and greater degree of intercoder reliability. Due to the increased reliability of the information and the inclusion of only contemporary campaigns, the GDADS 2.0 was selected for use in this project.

The GDADS 2.0 includes information on 426 digital activism campaigns from 100 countries beginning between 2010 and 2012. Information on the campaigns was obtained through content analysis of a variety of sources, including academic journals, conventional news sources, and websites known to publish information on digital activism. These source materials are included in the GDADS 2.0, which eschews traditional numeric coding for many variables and instead provides a substantial amount of textual information, including links to campaigns' digital media pages - such as social 
media accounts, blogs, or websites - and to third-party websites reporting on the campaigns.

For the identification and content analysis of these materials, campaigns were subject to strict inclusion criteria aimed at ensuring that all included campaigns conformed to the previously cited definition of a digital activism campaign. To be included in the data set, a campaign: (1) must have involved at least one instance of digital media use as a tactic or means of effecting social or political change; (2) must have been identified or described by a reliable third-party source; (3) could not have been initiated by a governmental or for-profit entity; (4) must have made an attempt to engage the general public; (5) had to collectively develop goals; (6) must have proposed a concrete solution to the issue being addressed and (7) had to have identified specific targets such as individuals, organizations, or policies against which action was to be taken. The strict inclusion criteria for the GDADS 2.0 means that the results of the study are not generalizable. Nonetheless, the GDADS 2.0 is the only data set of its kind, offering detailed information on the goals, tactics, events, and outcomes of digital activism campaigns, making it uniquely suited for identifying predictors of campaign success.

\section{Measures}

Several steps were taken to prepare the data for analysis. The GDADS 2.0 does not include measures for the primary independent variable: types of Internet activism used during the course of the campaign. Measures for this variable were instead constructed through a quantitative content analysis of the source materials listed in the 
GDADS 2.0. While approximately one-quarter to one-third of the original source materials are no longer accessible because the content has been restricted or removed, there was sufficient information available to engage in an intensive recoding of the source materials, allowing for the creation of additional variables. Additionally, all GDADS 2.0 variables for which information was presented as textual data were necessarily recoded into numeric variables in order to be included in the analysis. Following standard procedures for identifying variables for inclusion in the models, initial bivariate tests for association were conducted before constructing the final regression models (Long and Freese 2006).

\section{Dependent Variable}

Outcome. An ordinal measure for campaign outcome is included in the GDADS 2.0 and is measured with three possible outcomes: success (all goals identified during the analysis of the campaign were met), partial success (some goals of the campaign were achieved or the campaign was officially recognized by the target), and no success (no campaign goals were met). Similar to the definition provided by Gamson (1975), the GDADS 2.0 measures success based on whether a campaign achieved their stated goals and provides multiple levels of success. Herein, outcome is coded so that a higher value corresponds to greater success, with a ' 0 ' indicating no success, ' 1 ' indicating partial success, and '2' indicating total success. .

Thirty-nine cases were initially missing information regarding campaign outcome; however, a review of both source materials and the campaign descriptions included in the 
data set indicated that many such cases had achieved at least partial success before data collection ended, and were recoded accordingly

For some cases in the data set, missing data in the published GDADS 2.0 or the inaccessibility of source materials due to the restriction or removal of content meant that there was insufficient information for a reliable coding of the types of Internet activism used by a campaign. Several cases also had missing information for the dependent variable, campaign outcome. Additionally, a small number of cases within the published data appeared to have been coded erroneously and presented source materials from multiple campaigns as a single case or (in one case) provided information indicating that the campaign should not have qualified for inclusion in the GDADS 2.0. These cases were excluded from analysis. Finally, cases that were defined in in the textual campaign descriptions as ongoing at the time of data collection were excluded to avoid conflating unsuccessful campaigns with campaigns that had simply not been successful yet, yielding a total analytic sample of 358 digital activism campaigns.

\section{Independent Variables}

As previously noted, measures for the primary predictor of interest - the types of Internet activism used in the campaign - were not originally included in the GDADS 2.0, and were constructed through a quantitative content analysis of both the textual information included in the data set and the source materials linked in the data. This coding identified which of the four specific types of Internet activism - brochure-ware, facilitation of offline activism, participation in online actions, and online organizing conceptualized by Earl et al. (2010) - were used by a campaign. During the recoding 
process, dichotomous variables were created reflecting the presence (coded as ' 1 ') or absence (coded as ' 0 ') of each specific form of Internet activism throughout the course of the campaign. Each are described in detail below (a full description of the coding scheme is presented in Table 1).

Table 1: Indicators for Categories of Internet Activism

\begin{tabular}{|c|c|}
\hline Brochureware & E-mobilizations \\
\hline $\begin{array}{l}\text { Campaign or organization website } \\
\text { Blog posts } \\
\text { Web videos } \\
\text { Tweets (no hashtag use) }\end{array}$ & $\begin{array}{l}\text { Facebook event page } \\
\text { Protest coordination via Twitter } \\
\text { Event information shared on website, blog, or } \\
\text { forum }\end{array}$ \\
\hline Online Participation & Online Organizing \\
\hline $\begin{array}{l}\text { Facebook page/group } \\
\text { E-petition } \\
\text { Coordinated 'upvoting' of specific content } \\
\text { Tweeting with hashtag } \\
\text { Tweeting directed at target } \\
\text { Facebook comments on target's page } \\
\text { Profile avatar filters/blackouts/frames } \\
\text { Website blackouts } \\
\text { Photo-sharing sites } \\
\text { E-mail campaigns } \\
\text { DDoS attacks } \\
\text { Interactive protest websites } \\
\text { Crowdfunding localized actions } \\
\text { Online polls } \\
\text { Hacking attacks } \\
\text { Interactive website features } \\
\text { Video sharing } \\
\text { Photo sharing } \\
\text { Crowdsourcing policy } \\
\text { Interactive maps } \\
\text { Sharing of censored materials } \\
\text { Doxxing } \\
\text { Changing profile surnames }\end{array}$ & $\begin{array}{l}\text { Individual initiator organized campaign via } \\
\text { Internet } \\
\text { Campaign was organized by hacker collective } \\
\text { Loose blogger networks organized campaign } \\
\text { Loose organization formed and maintained } \\
\text { through online connections between users } \\
\text { No information on organizers, but movement } \\
\text { was wholly online }\end{array}$ \\
\hline
\end{tabular}

Brochureware. Following Earl et al.'s (2010) definition, Internet activism was defined as brochure-ware if it treated "the Internet not as an interactive medium but rather as a broadcast channel for information distribution" (429). Actions were coded as 
belonging to this category when they were primarily aimed at information distribution unrelated to mobilizing individuals for protest actions, and offered minimal or no opportunity for others to engage in participation with the campaign. Frequently included in this category were websites or website pages by formal organizations advocating for the campaign, formal blog posts or videos made by the campaign organizers, and citizen journalism via isolated blog posts, posting content to online video hosting sites such as YouTube, or tweets which showed no broader connection to a campaign via a campaign hashtag.

E-mobilizations. Internet activism in this category is defined as actions aimed at "Providing information on, logistical support for, and/or recruitment for offline protest events such as offline marches, rallies, convergence centers, etc." (Earl et al. 2010: 429). Campaigns that engaged in e-mobilizations most frequently did so by creating event pages on Facebook or circulating protest details through other forms of social media such as Twitter.

Online Participation. Earl et al.'s (2010) definition of online participation describes this type of Internet activism as:

providing actual avenues for participation while people are online, including relatively less confrontational actions such as online petitions and letter-writing and email campaigns, to moderately contentious forms of participation such as "website hauntings" to very contentious forms of participation such as denial of service actions that operate like virtual sit-ins in closing down websites (429).

In addition to the actions described by Earl et al., symbolic online actions intended to show support for a cause or connection with a campaign, such as displaying a campaignrelated profile photo or 'liking' a Facebook page, are also included in this category. 
The types of actions included in this category are diverse. Lower-level protest actions include symbolic gestures such as 'liking' of a social media page, joining a group on social media, or altering a profile photo (either through the use of a 'protest avatar' where the profile picture was replaced completely with one indicating support for a cause, or through the use of a special border or translucent overly with colors or imagery corresponding to the campaign). Moderate participation in online protest actions might include actions indirectly aimed at a target, such as advocating for a cause via social media and using a campaign hashtag to provide avenues for others to engage, or signing an e-petition. At the highest level, participation in online protest actions included direct correspondence with targets via email or social media, or denial of service (DDoS actions) or direct hacking attacks against a target. Due to the diversity of online protest actions included in campaigns, subcategories were created to examine potential associations with outcome. These categories distinguished between low-level expressions of solidarity (such as 'liking' a Facebook page), indirect actions against a target (such as signing an e-petition to later be delivered to the target), and direct actions against a target (such as direct hacking attacks or email campaigns). However, these subcategories did not emerge as significant during creation of the final regression models and were ultimately excluded from the analysis in favor of a dichotomous measure of online participation.

Online Organizing. Online organizing is a unique form of Internet activism "observed when entire campaigns and/or movements are organized online" (Earl et al. 2010:429). Campaigns engaging in online organizing did not include any in-person 
coordination by the initiators, and thus used the Internet to connect individuals instead of more traditional methods such as churches or community centers. While these campaigns did include offline actions in a small number of cases, the infrastructure of the campaign was located entirely online. For the majority of campaigns including online organizing, the online organization took the form of loose networks of bloggers coordinating online to achieve a specific goal.

Digital Media Type. The GDADS 2.0 includes measures for seven types of digital media: websites, forums, e-petitions, social networking sites, microblogs, blogs, and online videos. E-petitions were the only specific forms of digital media shown during bivariate analysis to have a significant relationship with the dependent variable, and are included for in the analysis. The GDADS 2.0 originally provided textual data for this variable, which was recoded into a dichotomous measure indicating the presence or absence of e-petition use over the course of the campaign.

\section{Control Variables}

Previous research identifies several factors that may influence the outcome of digital activism campaigns. Variables for many such factors are already included in the GDADS 2.0, including the presence of offline protests during the campaign, whether the target of the campaign was a government, private, or civic organization, and whether the target country was ruled by an authoritarian or democratic regime. During the coding process, measures were also constructed indicating the number of types of Internet 
activism used by a campaign $^{1}$, the number of types of digital media used by a campaign ${ }^{2}$, and the level of online or offline participation a campaign experienced. It should be noted that due to the limitations of the source materials, the levels of participation were coded according to identifiable instances of participation instead of a more conventional measure identifying the total number of participants. For online participation, the level of participation was identified as an approximate sum of all participation across all participatory media platforms - that is, the total identifiable number of tweets, Facebook 'likes', Facebook group members, e-petition signatures, and online comments, as well as the number of individual hacking attacks and website blackouts when such actions were included in the campaign. Because exact numbers were frequently unavailable, loose categories were constructed identifying six levels of participation: none, less than 100 instances of participation, 101-1000 instances of participation, 1001-10,000 instances of participation, 10,001-100,000 instances of participation, and 100,000+ instances of participation. For offline participation, the measure was constructed similarly, but the highest category identified campaigns with 10,000 or more instances of participation. While the levels of offline participation were constructed based on reported attendance numbers for protests or other events, these should still be thought of as instances of participation instead of a measure of the number of participants, as its possible that the same participants attended more than one event.

\footnotetext{
${ }^{1}$ The number of types of Internet activism used by the campaign was measured by totaling the values for all four Internet activism types, and ranged from 1-4. This measure was not identified as significant in bivariate analyses or initial regression models.

2 The number of types digital media used by the campaign was measured by totaling the values for all seven types of digital media, and ranged from 1-7. This measure was not identified as significant in bivariate analyses or initial regression models.
} 
Similarly, in an effort to account for the diversity of causes addressed by campaigns in the GDADS 2.0, a measure identifying the type of issue addressed by a campaign was also constructed. Campaigns were coded as belonging to one of six categories: social justice (for campaigns addressing human rights issues such as Stateauthorized violence, healthcare access or issues rooted in gender, sexuality, race, or ethnicity), democracy and rule of law (for campaigns aimed at government reform/replacement or legal reforms), economics (for campaigns focusing on both largescale economic issues such as wealth redistribution and smaller-scale efforts related to more localized budget concerns), environmental (for campaigns aiming at environmental preservation or animal rights), information and expression (for campaigns focused on free speech rights and unrestricted information flows), and an 'other' category which included cases not belonging to other categories. The 'other' category included campaigns focused on religious rights issues unrelated to the suppression of religious practices and those addressing crisis response practices, as well as consumer and entertainment campaigns not related to social justice or environmental issues (for example, protests against a corporate logo change or campaigns protesting against the cancellation of television series).$^{3}$

\footnotetext{
${ }^{3}$ The measure for the six issue types constructed during data preparation was created based on issue types identified in the textual campaign descriptions included in the GDADS2. The initial data included 26 different issues types; however, small cell sizes required these categories to be significantly condensed before they could be considered for inclusion in the final data analysis. Using a standard approach for variable exclusion, bivariate tests and initial regression models including the measures of issue type showed no significant relationship to outcome, leading to omission from final models. However, these initial tests should not be considered to have demonstrated a null relationship between the type of issue a campaign is addressing and the outcome of the campaign. It is quite possible that the condensing of categories necessary for analysis simply precluded identifying any significant relationship.
} 
In order to assure parsimony, purposeful selection was used to identify control variables for inclusion in the regression models. Theoretically relevant variables were identified, and bivariate analyses were used to determine if there was a significant relationship that should be accounted for in the final analysis. Initial selection tested relationships between outcome and several types of digital media, as well offline participation, target type, governmental structure in the initiator country, and levels of participation during the campaign.

The occurrence of offline mobilizations not facilitated through the Internet (referred to as 'offline mobilizations' throughout the rest of the analysis and discussion) during the campaign are also included in the final regression models for comparison with e-mobilizations. This measure was constructed by recoding an included measure of any offline participation during the course of the campaign (also initially a textual variable) into a dichotomous measure, and then computing a new measure indicating if a campaign experienced offline participation without engaging in e-mobilizations. Other variables of theoretical interest - the type of target, governmental structure, levels of online and offline participation during the campaign, and issue type - were not shown during bivariate analysis to be significantly related to campaign success, and are excluded from the final analysis ${ }^{4}$.

\footnotetext{
${ }^{4}$ Despite the apparent absence of any relationship during initial significant tests, variables excluded in the final models were included in initial regressions to ensure the lack of any significant effect. Results regression models including the type of target, governmental structure, levels of online and offline participation, and issue type yielded similar results and those excluding them yielded similar results, and so these variables were excluded from final models.
} 


\section{Analytic Plan}

Descriptive statistics are presented for all variables included in the analysis. Bivariate associations between the independent and dependent variables are also presented. Finally, a series of ordinal logistic regression models are used to further assess the significance of the relationships between specific types of Internet activism, media types, and campaign success.

The dependent variable, campaign outcome, is an ordered categorical measure indicating that a campaign achieved total success, partial success, or no success. As such, ordinal regression is a more appropriate choice for analysis than a linear regression (OLS) model because equal distances between outcome categories cannot be assumed. Similar to logistic regression with a dichotomous dependent variable, ordinal models predict the probability of an observed case being in a given category of the ordinal dependent variable. For this study, ordinal logistic regression will show a campaign's likelihood of achieving complete success compared to partial or no success, and of achieving complete or partial success compared to no success. Regression coefficients are generated using the following model (Long and Freese 2006):

$$
\operatorname{Pr}\left(\text { success }=m \mid \mathrm{x}_{i}\right)=F\left(\tau_{m}-\mathrm{x} \beta\right)-F\left(\tau_{m-1}-\mathrm{x} \beta\right)
$$

where

$$
\begin{aligned}
\mathrm{x} \beta & =\beta_{\text {brochurebrochure }}+\beta_{\text {emobilize }} \text { emobilize }+\beta_{\text {online }} \text { online } \\
& +\beta_{\text {organizeorganize }}+\beta_{\text {epetition }} \text { epetiton }+\beta_{\text {offline }} \text { offline }
\end{aligned}
$$

One assumption of ordinal logistic regression is that the relationship between independent variables and each category of the dependent variable is the same (the 
proportional odds assumption) and that one coefficient can describe the relationship to all pairs of outcome groups (Hosmer, Lemeshow, and Sturdivant 2013; Long and Freese 2006). This assumption is validated using a test of parallel lines; if the assumption is violated, multinomial logistic regression models may be more appropriate. Before finalizing regression models, the ordinal outcome measure was verified to not violate the proportional odds assumption in the final regression model $(\mathrm{p}=.34)$. The results using an ordinal measure of outcome were also compared to results using a dichotomous outcome measure, and were showing to identify more significant relationships. Based on these tests, ordinal logit regression was used in all models. 


\section{Chapter 4: Results}

\section{Descriptive Results}

Table 2 presents descriptive results for all main predictors of interest as well as covariates included in the final regression models. Among campaigns included in the sample, approximately one-third (35\%) were completely successful and just under onequarter (23\%) achieved partial success. A plurality of campaigns (43\%) were entirely unsuccessful in meeting their stated campaign goals before ending.

\section{Table 2: Descriptive Statistics}

Outcome:

Frequencies

Proportion

Successful

\section{Partially Successful}

Unsuccessful

Types of Internet Activism:

Brochureware

125

81

152

255

74

274

Online Participation

Online Organizing

Digital Media Type:

E-petition Use

Offline Mobilizations

$\mathrm{N}=358$

Descriptive results for the types of Internet activism used indicate a great deal of diversity among campaigns. Online participation was the most frequently used type of Internet activism, with results showing it to be present in $77 \%$ of campaigns. A substantial majority of campaigns (71\%) also used brochureware as part of their information dissemination tactics. In contrast, e-mobilizations were only present it less than one-quarter $(21 \%)$ of campaigns and online organizing was comparatively rare, with only $9 \%$ of campaigns being organized entirely online. The specific digital media included in the final regression models - e-petitions - were used by less than half of 
campaigns (26\%). Offline mobilizations not facilitated via the Internet were present in $34 \%$ of campaigns.

The primary research question asks: are certain types of Internet activism more likely to be effective? Table 3 prevents bivariate analyses that illustrate the distribution of Internet activism types and predictor variables across outcomes, and identify which of these relationships are approaching significance. It is important to note that a lower significance threshold (.10 instead of .05) was established due to the relatively small size of the sample.

Results show that a higher number of successful campaigns (74.4\%) used brochureware compared to partially successful campaigns (70.4\%) and unsuccessful campaigns $(69.1 \%)$. Though present in a minority of campaigns, online organizing was also present in a larger percentage of successful campaigns (9.6\%) than unsuccessful campaigns (7.9\%); though it was used most often by partially successful campaigns (9.9\%). In contrast, e-mobilizations appear to be negatively linked to success, with this type of Internet activism being present less commonly in successful campaigns (16.8\%), than partially successful (17.3\%) or unsuccessful campaigns (25.7\%). Interestingly, amongst types of Internet activism, e-mobilizations were also the only primary predictor variable to approach significance $(\mathrm{p}=.07)$.

The bivariate distribution of online participation presents a more U-shaped pattern with a greater number of cases represented in the completely successful and unsuccessful categories $-80.8 \%$ of successful campaigns included online participation and $77.0 \%$ of unsuccessful campaigns included online participation, while it was present in only $69.1 \%$ 
of partially successful campaigns. Surprisingly, offline mobilizations also exhibit a Ushaped pattern, with these actions being present most often in partially successful campaigns (40.7\%), and less frequently in unsuccessful (32.9\%) or totally successful (32.0\%) campaigns.

Table 3: Distribution of Outcome Across Predictors

\begin{tabular}{|c|c|c|c|}
\hline & $\begin{array}{l}\text { No. of Successful } \\
\text { Campaigns (\%) }\end{array}$ & $\begin{array}{c}\text { No. of Partially } \\
\text { Successful } \\
\text { Campaigns (\%) }\end{array}$ & $\begin{array}{c}\text { No. of } \\
\text { Unsuccessful } \\
\text { Campaigns (\%) }\end{array}$ \\
\hline Total & $125(34.9)$ & $81(22.6)$ & $152(42.5)$ \\
\hline \multicolumn{4}{|c|}{ Brochureware } \\
\hline Yes & $93(74.4)$ & $57(70.4)$ & $105(69.1)$ \\
\hline No & $32(25.6)$ & $24(29.6)$ & $47(30.9)$ \\
\hline \multicolumn{4}{|c|}{ E-mobilizations* } \\
\hline Yes & $21(16.8)$ & $14(17.3)$ & $39(25.7)$ \\
\hline No & $104(83.2)$ & $67(82.7)$ & $113(74.3)$ \\
\hline \multicolumn{4}{|c|}{ Online Participation } \\
\hline Yes & $101(80.8)$ & $56(69.1)$ & $117(77.0)$ \\
\hline No & $24(19.2)$ & $25(30.9)$ & $35(23.0)$ \\
\hline \multicolumn{4}{|c|}{ Online Organizing } \\
\hline Yes & $12(9.6)$ & $8(9.9)$ & $12(7.9)$ \\
\hline No & $113(90.4)$ & $73(90.1)$ & $140(92.1)$ \\
\hline \multicolumn{4}{|c|}{ E-petition Use* } \\
\hline Yes & $28(22.4)$ & $17(21.0)$ & $47(30.9)$ \\
\hline No & $97(77.6)$ & $64(79.0)$ & $105(69.1)$ \\
\hline \multicolumn{4}{|c|}{ Offline Mobilizations } \\
\hline Yes & $40(32.0)$ & $33(40.7)$ & $50(32.9)$ \\
\hline No & $85(68.0)$ & $48(59.3)$ & $102(67.1)$ \\
\hline
\end{tabular}

The distribution of e-petition use across outcomes is approaching significance $(\mathrm{p}=.10)$ and suggests a negative relationship. E-petition use was included in $30.9 \%$ of unsuccessful campaigns compared to only $22.4 \%$ of successful and $21.0 \%$ of partially successful campaigns. 


\section{Ordinal Logistic Regression Results Predicting Campaign Outcome}

Table 4 presents results from the ordinal logistic regression determining the relationship between the types of Internet activism and digital media used in a campaign and the campaign outcome. The relationship between all predictors and outcome was found to meet the proportional odds assumption, indicating that the relationship between all pairs of outcome groups (total success compared to partial or no success, and total or partial success compared to no success) are the same, and so only one set of odds ratios is presented. Models 1 through 4 focus on the baseline relationships between different types of Internet activism and success. Model 5 then includes all types of Internet activism to assess the association between these predictors in combination and outcome. Finally, Model 6 is the full model, which incorporates all types of internet activism and controls for e-petition use and offline mobilizations.

Results from Models 1 through 4 present odds ratios indicating that relative to campaigns not utilizing each respective type of Internet activism, the odds of a campaign achieving complete success compared to partial or no success, or complete or partial success compared to no success, were $23 \%$ [100(1.23-1)] higher in campaigns that included brochureware, 37\% lower in campaigns that included e-mobilizations, $15 \%$ higher in campaigns including participation in online protest actions, and 19\% higher in campaigns involving online organizing. However, e-mobilizations were the only predictor approaching significance in these initial models $(\mathrm{p}=.06)$.

Model 5 indicates that after accounting for the influence of the other types of Internet activism, the relationships remain largely unchanged and e-mobilizations are still 





the only statistically significant predictor of success. Accordingly, the association of e-mobilizations remains unchanged and still significant $(\mathrm{p}=.06)$.

Model 6 presents final results after accounting for e-petition use and offline mobilizations. The final model suggests that net of controls, e-mobilizations significantly decrease the odds of success by $53 \%(\mathrm{p}=.01)$. The modest effect sizes for brochureware and online participation and the minimal effect size for online organizing still do not approach significance in the final model. However, the significant negative relationship between e-mobilizations and success supports the initial hypothesis that the types of Internet activism used during the course of the campaign will have varying relationships to campaign outcome.

Both e-petition use and offline mobilizations are shown to have a negative effect on success, with the presence of e-petitions significantly decreasing the odds of success by $47 \%$ ( $\mathrm{p}=.01)$. Offline mobilizations also decrease the odds of success by $31 \%$, but the effect is not significant. The significant relationship between e-petition use and outcome does provide marginal support for Hypothesis 2 suggesting that the specific types of digital media used by a campaign will influence outcome. 


\section{Chapter 5: Discussion}

Previous work on Internet activism has indicated that digital tools are used by activists in a variety of ways for a variety of purposes, and that these multiple modes of online engagement differ in their implications for social movement theory (Earl et al. 2010). Additionally, the specific forms of media through which Internet activism occurs have been shown to vary in both the benefits they offer to activists and the risks they pose (Garrett 2006). Based on these previous findings, two hypotheses were developed predicting how different types of Internet activism (as defined in the typology presented by Earl et al.) and the tools through which it occurs may impact activists' efficacy: (1) that certain types of Internet activism would be more effective for meeting stated goals and (2) that certain digital media would be more effecting for achieving stated goals.

Both hypotheses were supported by the results of ordinal regression analyses. In particular, e-mobilizations (the use of the Internet to facilitate offline protest actions) and e-petitions were both significantly associated with a decreased likelihood of total success compared to partial or no success in meeting stated campaign goals, and of total or partial success compared to no success. In contrast, the other forms of Internet activism included in the analysis - brochureware, online participation, and online organizing - do not evidence significant relationships with campaign success.

\section{Effectiveness of Types of Internet Activism}

One of the goals of this analysis was to explore how activism occurring in an online context may differ from more traditional forms of activism that rely on offline engagement. As such, one of the most interesting findings is the identification of a 
negative association between e-mobilizations and success. Much of the literature on Internet activism presumes that e-mobilizations should be the end goal of online engagement, and much work on the efficacy of online activism has concerned itself with the effectiveness of using digital tools to mobilize constituents for protest actions (Boulianne 2015; Kristofferson et al. 2014; Robles et al. 2013; Schumann and Klein 2015; Valenzuela 2013; Vissers and Stolle 2014). However, the apparent negative relationship between e-mobilizations and successful outcomes suggests that a more nuanced examination of the impacts of such mobilizations is necessary. This is especially true when considering that mobilizations not organized via the Internet were not found to significantly relate to campaign success.

Previous work on social movement outcomes suggest that offline protest actions are a crucial tactic for achieving success (Piven and Cloward 1977). If this holds true for campaigns utilizing digital tactics, e-mobilizations would be expected to increase a campaigns' odds of success. That the opposite was observed and different relationships to success emerged for e-mobilizations and offline mobilizations (protest actions or similar organized via offline channels) suggests the character of mobilizations organized through online networks is distinctly different. This is aligned with the previous work by Earl et al. (2010), who found that e-mobilizations were sometimes linked to a need to update models of social movement formation. It also agrees with Bennet and Segerberg's (2012) finding of a new logic of connective action created by individualized participation through the Internet. Similarly, the notion that e-mobilizations and offline mobilizations differ is supported by previous work comparing the socio-demographic characteristics of 
attendees at protest events organized online to those at more traditionally-organized protests; differences emerged suggesting those mobilized through the Internet were younger, better educated, and less likely to be affiliated with a formal organization (Anduiza et al. 2014; Enjolras, Steen-Johnsen, and Wollebaek 2013).

The latter characteristic - organizational affiliation - may be the most relevant factor for explaining why mobilizations that originate online appear linked to a decrease in a campaign's odds of success. Individuals' online social networks are typically comprised of a combination of strong and weak ties, but frequently include a greater proportion of the latter. Individuals use digital media to connect with others they are close to, but digital tools are also used to maintain connections to distant acquaintances or, in many cases, strangers. These weak ties may be useful for activism in many cases; dissemination of the recruitment-related content that facilitates mobilization relies on information flowing across networks, which relies on these weak ties (González-Bailón et al. 2011, 2013). Similarly, these loose connections between individuals have been shown to be essential for bridging networks to facilitate information exchange and create a temporary movement infrastructure (Walgrave et al. 2011). However, while such weak ties may be useful for spreading information and orchestrating singular actions, it is primarily strong ties that may "produce closely meshed, enduring groups" (Stalder 2013:44). As such, utilizing online networks to mobilize participants may be more likely to result in 'flash activism' that relies on a momentary organization and mobilization of individuals which dissipates quickly after mobilization. These types of mobilizations can be useful for addressing certain causes, but may be insufficient for building a lasting 
social movement infrastructure for which participant engagement is necessary over the long-term (Earl 2015). Organizations have been credited with helping to maintain connections between individuals over the long-term (Gamson 1975), and as such their absence (in online settings) may increase the odds of a campaign collapse before success is achieved. If many issues still require long-term engagement to address, the ephemeral nature of many e-mobilizations may be ill-suited to the task.

A further possibility is that campaigns including e-mobilizations - and offline protests in general - were predisposed to failure. The results of bivariate analyses presented in the previous chapter indicated that a majority of successful campaigns achieved their stated goals without the inclusion of any form of offline action. While not verifiable, it is possible that campaigns including offline actions had loftier goals less easily realized through the use of online participation alone, and organized for offline protests in the hopes that more disruptive, higher-investment actions would provide a benefit. If true, such campaigns would already be more likely to collapse before achieving any degree of success, regardless of whether they facilitated such protests via the Internet or through offline organizing. Coupled with the potential for e-mobilizations to result in flash activism but not a lasting movement, this may explain both why campaigns that utilized e-mobilizations were less likely to achieve success, and why this same relationship did not emerge for offline mobilizations, which may have involved more formal organization and thereby more endurance. 


\section{E-petition Use and Implications for Efficacy}

E-petition use was included in the analysis as one measure of the types of digital media used by a campaign. However, when discussing e-petitions it is important to note that they are somewhat unique in that they occupy a position as both a type of digital media and a form of online participation, and they may be significant as both. As a form of digital media, they are typically hosted on 'warehouse sites' - specific platforms that allow anyone to create and maintain an e-petition (Earl and Kimport 2011). Links to these warehouse sites are frequently distributed across numerous other platforms, allowing individuals to access and sign the petition. Through this process, they become a form of media a campaign may use to offer an avenue for online participation.

There are several characteristics of e-petitions as both a type of media and a type of online participation that, in combination, may contribute to their observed negative relationship with campaign success. E-petitions' hosting on warehouse sites leaves them fairly removed from most people's day-to-day online engagement. Such sites are typically visited only briefly when an e-petition is signed, after which point they may be easily forgotten. For many users, the only recurring exposure may be in the form of follow-up e-mails, which may or may not be directly related to the campaign a signer initially supported and may or may not be viewed by the receiver.

As a form of online participation, engagement with a cause through other forms of media may offer more provide more prolonged exposure. 'Liking' a campaign on Facebook or 'following' one on Twitter leads to inclusion of content published by the campaign in a participant's feed, providing recurring exposure to a cause and continued 
opportunities for engagement in the form of sharing or commenting on postings. In contrast, e-petitions do not afford this ongoing connection to a campaign.

A second consideration is that signing an e-petition is a relatively individualistic, low-threshold action. Coupled with the fact that signing one is such a brief event, it possible that as a form of online participation e-petitions are simply ineffective in garnering more than token support for a cause. Other avenues of online participation typically involve either a greater time investment, such as when composing messages for an email campaign, or a commitment to more continuing engagement, even if it is only in the form of knowing content will be displayed on the Facebook newsfeed. Additionally, e-petition signatories are rarely connected together through the platform or the participation; few opportunities for engagement are afforded by the warehouse sites on which e-petitions are hosted, and no community emerges around them allowing participants to interact. If, as discussed above, the creation of a lasting infrastructure is both important for campaign success and more difficult to achieve as formal organizations are less frequently involved, e-petitions may be especially ineffective at fostering the creation of even a loose organizational form that could benefit a campaign. This may explain why e-petitions are negatively related to success despite the apparent positive relationship between success and online participation as a whole.

\section{Limitations}

Taken together, the findings suggest that certain types of Internet activism and certain forms of digital media may be more effective in building a lasting movement infrastructure. However, there are several limitations to the study that must be 
considered. Most notable is the issue of selection bias in the sampling of campaigns included in the GDADS 2.0. The data's strict inclusion criteria do not allow for a representative sample of all activism campaigns and precludes generalizing findings beyond those cases included in the GDADS 2.0. Additionally, the use of cross-sectional data limits the ability to make strong claims about the causal directions of the determined relationships. The small sample size also led to low cell counts for some categories during regression analysis, meaning that the significant relationships identified during analysis should be interpreted with caution. Additionally, given that the unit of analysis in the data is at the campaign level and not the movement level, it is also important to note that the findings may not be generalizable to social movements as a whole.

\section{Future Directions}

These findings identify new implications for the shift towards decreasing reliance on traditional, hierarchical organizations and towards personalized, loosely-organized participation facilitated via the Internet. Previous work has identified changes to how social movements form due to this trend (Bennett and Segerberg 2012; Earl et al. 2010); this study suggests possible implications for efficacy as well. Offline protest actions are frequently identified as an important part of social movements' repertoires of contention (Gamson 1975; Piven and Cloward 1977). If e-mobilizations are less effective than offline mobilizations, it is important to consider what, if any, other tactics are effective for movements utilizing a logic of connective action. Based on the findings of this exploratory study, numerous opportunities emerge for future work engaging in more nuanced examinations of the myriad ways digital tools are used by activists. In particular, 
work aimed at further identifying differences between e-mobilizations and mobilizations organized without the Internet may prove beneficial to furthering understanding of why these two means of mobilizations have differing relationships to success. Future explorations on efficacy would also do well to examine relationships between online participation in its varying forms and campaign outcomes.

Additionally, in considering the presented findings it bears restating that the operationalization of success in the original data is not necessarily canonical. While there is merit to defining success in terms of stated campaign goals, other work has addressed the possibility of measuring success by other metrics (Amenta and Young 1999; McAdam 1999). It is possible that operationalizing success in terms of other collective goods, increased public opinion, or biographical consequences may yield very different results. For example, some of the affordances of ICTs - such as broad reach and personalized communications - may be well-suited to increasing public opinion through awareness raising even when they have little effect on achieving stated goals. Both the negative relationship between e-mobilizations and outcome and the null findings regarding other forms of Internet activism suggest that the effectiveness of online activism may be better discussed using alternative definitions of success.

Further, work examining the general usefulness of Internet activism may be beneficial in determining how digital tools might indirectly impact outcomes. In considering previous findings on the unique characteristics of online activism, several factors emerge to suggest that such tools may be especially useful in specific instances. For example, activists who make use of the Internet as a 'space of autonomy' or 'sphere 
of dissidence' may find it effective for shaping public perception in a movement's favor (Aouragh and Alexander 2011; Castells 2012). This is especially true in the same situations where e-mobilizations may be predisposed to failure; the Internet as an alternative space may be most useful in situations where the goal is difficult to achieve, the stakes are high, and the target has substantial power and authority to resist activists' efforts. This provides one potential avenue for future research; in particular, the role of brochureware and online organizing in activists' use of online space may yield especially useful insights for further identifying how the Internet is changing social movement processes.

Similarly, the Internet as a means of creating the 'disruption' identified as important by previous scholarship is a promising area for future study. Online participation may be especially useful in this regard; while many types of online action are not necessarily capable of creating the same sorts of disruptions as the offline actions traditionally included in movements' repertoires of contention, such as strikes, boycotts, or protests, they may still have potential to disrupt 'business as usual' in other ways. The affordances of modern technology allow for increased surveillance of government and corporate entities by citizens, who are then able to use the Internet to increase accountability through forms of online participation, such as hashtags or online commenting campaigns. Particularly in developed nations, these situations may find the sort of flash activism that frequently emerges via online activism to be an effective tool for increasing public awareness of wrongdoings and challenging dominant powers. 
There is also opportunity for exploration of the diminished role of resources identified by some previous work. While resources may not be as vitally important as they were previous to online communication, it is important to identify when the accumulation of resources may still be necessary for movements or campaigns, even for those in which formal organizations or not present. Similarly, future work could consider the necessity of alternative types of resources; e-mobilizations have been found to rely on the connections between individuals in general, and the connections of influential online actors in particular. This suggests that resources are still necessary, but that it is social capital and not economic capital that has become most important.

Finally, any subsequent empirical work following these suggestions would also benefit greatly from data collection efforts that track the course of movements over time to allow not only for more causal determinations between digital tactics and outcomes, but also for a better understanding how activists' timing regarding their use of digital tools may impact the course of a campaign or movement. The use of brochureware in the early stages of movement formation when, for example, the Internet is serving as a space of autonomy to spread a movement message, may have a drastically different impact on a movement's trajectory than the use of brochureware when a movement is more established. Similarly, e-mobilizations may be more effective at exerting pressure on a target when they occur early on a movement compared to when they occur as a movement is already approaching collapse. The role of timing is an especially important factor that remains unaccounted for in much scholarly work. 


\section{Conclusion}

This exploratory analysis provides insight into how the different ways that activists use the Internet relates to their effectiveness in creating social change. By empirically addressing the issue of efficacy, the findings add to the literature and contribute to the existing debate regarding whether increasing reliance on the Internet is a benefit or hindrance for social movements. Results suggest that certain types of online activism and certain platforms for participation are negatively related to success in at least some cases, offering support for skepticism regarding the Internet's ability to effectively mobilize a constituency in a meaningful way. Similarly, the effect of epetitions on success validates concerns regarding engagement in low-threshold online actions.

These findings identify new implications for the shift towards decreasing reliance on traditional, hierarchical organizations and towards personalized, loosely-organized participation facilitated through ICTs. Previous work has identified changes to how social movements form due to this trend (Bennett and Segerberg 2012; Earl et al. 2010); this study suggests possible implications for efficacy as well. Offline protest actions are frequently identified as an important part of social movements' repertoires of contention (Piven and Cloward 1977). If e-mobilizations are less effective than offline mobilizations, it is important to consider what, if any, other tactics are effective for movements utilizing a logic of connective action. It is also important to consider alternative definitions of success, as well as the way that the timing of different digital tactics' use may impact the course of a movement. In doing so, a more comprehensive 
understanding of the interplay between digital tactics, digital tools, and social movement formation and outcomes may be achieved. 


\section{References}

Amenta, Edwin and Michael P. Young. 1999. "Making an Impact: Conceptual and Methodolical Implications of the Collective Goods Criterion." Pp. 22-41 in How Social Movements Matter, edited by M. Giugni, D. McAdam, and C. Tilly. Minneapolis, MN: University of Minnesota Press.

Anduiza, Eva, Camilo Cristancho, and José M. Sabucedo. 2014. "Mobilization through Online Social Networks: The Political Protest of the Indignados in Spain." Information, Communication \& Society 17(6):750-64.

Aouragh, Miriyam and Anne Alexander. 2011. "The Arab Spring| the Egyptian Experience: Sense and Nonsense of the Internet Revolution." International Journal of Communication 5:1344-58.

Bennett, W.Lance and Alexandra Segerberg. 2012. "The Logic of Connective Action." Information, Communication \& Society 15(5):739-68.

Bennett, W.Lance, Alexandra Segerberg, and Shawn Walker. 2014. "Organization in the Crowd: Peer Production in Large-Scale Networked Protests.” Information, Communication \& Society 17(2):232-60.

Bimber, Bruce, Andrew J. Flanagin, and Cynthia Stohl. 2005. "Reconceptualizing Collective Action in the Contemporary Media Environment." Communication Theory 15(4):365-88.

Bonilla, Yarimar and Jonathan Rosa. 2015. "\#Ferguson: Digital Protest, Hashtag Ethnography, and the Racial Politics of Social Media in the United States." American Ethnologist 42(1):4-17.

Boulianne, Shelley. 2015. "Social Media Use and Participation: A Meta-Analysis of Current Research.” Information Communication \& Society 18(5):524-38.

Brunsting, S. and T. Postmes. 2002. "Social Movement Participation in the Digital Age: Predicting Offline and Online Collective Action.” Small Group Research 33(5):52554.

Castells, Manuel. 1999. "Grassrooting the Space of Flows.” Urban Geography 20(4):294-302.

Castells, Manuel. 2012. Networks of Outrage and Hope: Social Movements in the Internet Age. Malden, MA: Polity Press.

Couldry, Nick. 2015. “The Myth of 'us': Digital Networks, Political Change and the Production of Collectivity." Information, Communication \& Society 18(6):608-26. 
Earl, Jennifer. 2010. "The Dynamics of Protest-Related Diffusion on the Web." Information, Communication \& Society 13(2):209-25.

Earl, Jennifer. 2015. "The Future of Social Movement Organizations: The Waning Dominance of SMOs Online." American Behavioral Scientist 59(1):35-52.

Earl, Jennifer, Heather Mckee Hurwitz, Mejia Mesinas, Margaret Tolan, and Ashley Arlotti. 2013. "This Protest Will Be Tweeted." Information, Communication \& Society 16(4):459-78.

Earl, Jennifer, K. Kimport, G. Prieto, C. Rush, and K. Reynoso. 2010. "Changing the World One Webpage At a Time: Conceptualizing and Explaining Internet Activism." Mobilization 15(4):425-46.

Earl, Jennifer and Katrina Kimport. 2011. Digitally Enabled Social Change. Cambridge, MA: The MIT Press.

Enjolras, Bernard, Kari Steen-Johnsen, and Dag Wollebaek. 2013. "Social Media and Mobilization to Offline Demonstrations: Transcending Participatory Divides?" New Media \& Society 15(6).

Fenton, Natalie. 2011. "Alternative Media and Social Networking Sites: The Politics of Individuation and Political Participation." The Communication Review 14(3):17996.

Gamson, Williiam A. 1975. The Strategy of Social Protest. Belmont, CA: Wadsworth Publishers.

Garrett, R.Kelly. 2006. "Protest in an Information Society." Information, Communication \& Society 9(2):202-24.

Giugni, Marco G. 1998. "Was It Worth the Effort? The Outcomes and Consequences of Social Movements." Annual Review of Sociology 98:371-93.

González-Bailón, Sandra, Javier Borge-Holthoefer, and Yamir Moreno. 2013. "Broadcasters and Hidden Influentials in Online Protest Diffusion." American Behavioral Scientist 57(7):943-65.

González-Bailón, Sandra, Javier Borge-Holthoefer, Alejandro Rivero, and Yamir Moreno. 2011. "The Dynamics of Protest Recruitment through an Online Network." Scientific Reports 1:1-7.

Gurak, Laura. 2014. "Trust and Internet Activism: From Email to Social Networks." Pp. 7-19 in Cyberactivism on the Participatory Web, edited by M. McCaughey. New York, NY: Routledge. 
Hosmer, David W., Stanley Lemeshow, and Rodney X. Sturdivant. 2013. "Logistic Regression Models for Multinomial and Ordinal Outcomes." Applied Logistic Regression 269-311.

James, Rina. 2014. "Digital Media and Social Movements : The Role of New Media in the Outcome of Proposition 8." Young Scholars in Writing 11:17-26.

Joyce, Mary, Philip Howard, and Antonio Rosas. 2013. "Global Digital Activism Data Set Version 1.0.” Digital Activism Research Project.

Joyce, Mary, Antonio Rosas, and Philip Howard. 2013. Digital Activism \& Non-Violent Conflict. Seattle, WA: University of Washington.

Kristofferson, Kirk, Katherine White, and John Peloza. 2014. "The Nature of Slacktivism: How the Social Observability of an Initial Act of Token Support Affects Subsequent Prosocial Action.” Journal of Consumer Research 40(6):114966.

Van Laer, Jeroen and Peter Van Aelst. 2010. "Internet and Social Movement Action Repertoires.” Information, Communication \& Society 13:8(2010):1146-71.

Long, J.Scott and Jeremy Freese. 2006. Regression Models for Categorical Dependent Variables Using Stata. Second. College Station, TX: Stata Press.

Maireder, A. and C. Schwartzenegger. 2011. "A Movement of Connected Individuals: Social Media in the Austrian Student Protests 2009." Information, Communication \& Society 15(2):1-25.

McAdam, Doug. 1999. “The Biographical Impact of Activism.” Pp. 117-46 in How Social Movements Matter, edited by M. Giugni, D. McAdam, and C. Tilly. Minneapolis, MN: University of Minnesota Press.

McAdam, Douglas. 1982. "Political Process and The Development of Black Insurgency." in Political Process and the Development of Black Insurgency. Chicago: University of Chicago Press.

Mercea, Dan and Andreas Funk. 2014. "The Social Media Overture of the Pan-European Stop-ACTA Protest: An Empirical Examination of Participatory Coordination in Connective Action." Convergence: The International Journal of Research into New Media Technologies 1-26.

Milan, Stefania. 2015. "From Social Movements to Cloud Protesting: The Evolution of Collective Identity." Information, Communication \& Society 18(8):887-900.

Milan, Stefania and Arne Hintz. 2013. "Networked Collective Action and the Institutionalized Policy Debate: Bringing Cyberactivism to the Policy Arena?" 
Policy and Internet 5(1):7-26.

Newman, Nic. 2012. Reuters Institute Digital News Report 2012. Oxford, England.

Piven, Frances and Richard Cloward. 1977. Poor People's Movements: Why They Succeed, How They Fail. New York, NY: Random House.

Polletta, Francesca. 1998. "Contending Stories: Narrative in Social Movements." Qualitative Sociology 21(4):419-46.

Postmes, Tom and Suzanne Brunsting. 2002. "Collective Action in the Age of the Internet: Mass Communication and Online Mobilization." Social Science Computer Review 20(3):290-301.

Robles, José Manuel, Stefano De Marco, and Mirko Antino. 2013. "Activating Activists: The Links Between Political Participation and Digital Political Participation." Information, Communication \& Society 16(6):856-77.

Salter, Lee. 2014. "Emergent Social Movements in Online Media and States of Crisis: Analyzing the Potential for Resistiance and Repression Online." Pp. 257-80 in Cyberactivism on the Participatory Web, edited by M. Mccaughey. New York, NY: Routledge.

Schumann, Sandy and Olivier Klein. 2015. "Substitute or Stepping Stone? Assessing the Impact of Low-Threshold Online Collective Actions on Offline Participation." European Journal of Social Psychology 45(3):308-22.

Segerberg, Alexandra and W.Lance Bennett. 2011. "Social Media and the Organization of Collective Action: Using Twitter to Explore the Ecologies of Two Climate Change Protests." The Communication Review 14(3):197-215.

Shirky, Clay. 2011. "The Political Power of Social Media: Technology, the Public Sphere, and Political Change." 90(1):1-12.

Shulman, Stuart. 2009. "The Case Against Mass E-Mails: Perverse Incentives and Low Quality Public Participation in U.S. Federal Rulemaking." Policy \& Internet $1(1): 23-53$.

Smith, Jackie. 2001. "Globalizing Resistance: The Battle of Seattle and the Future of Social Movements." Mobilization 6(1):1-20.

Stalder, Felix. 2013. Digital Solidarity. Mute Books.

Tarrow, Sidney. 1997. "Social Movements: Readings on Their Emergence, Mobilization, and Dynamics." Pp. 328-39 in Movements in Action: Strategies and Tactics, edited by D. McAdam and D. Snow. Los Angeles, CA: Roxbury Publishing Company. 
Tilly, Charles. 1978. From Mobilization to Revolution. New York, NY: Random House.

Tilly, Charles and Lesley J. Wood. 2013. Social Movements 1768-2012. 3rd ed. New York, NY: Routledge.

Valenzuela, Sebastián. 2013. "Unpacking the Use of Social Media for Protest Behavior: The Roles of Information, Opinion Expression, and Activism." American Behavioral Scientist 57(7):920-42.

Vissers, Sara and Dietlind Stolle. 2014. "Spill-Over Effects Between Facebook and On/Offline Political Participation? Evidence from a Two-Wave Panel Study." Journal of Information Technology \& Politics 11(3):259-75.

Walgrave, Stefaan, W.Lance Bennett, Jeroen Van Laer, and Christian Breunig. 2011. "Multiple Engagements and Network Bridging in Contentious Politics: Digital Media Use of Protest Participants." Mobilization 16(3):325-50.

Wright, Scott. 2016. “'Success' and Online Political Participation: The Case of Downing Street E-Petitions." Information, Communication \& Society 19(6):843-57. 